\title{
Long-term impact of radial artery harvest on forearm function and symptoms: A comparison with leg vein
}

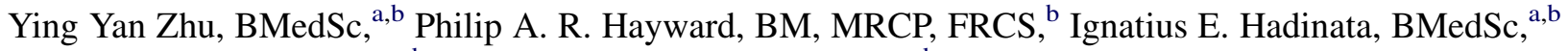 \\ George Matalanis, FRACS, ${ }^{\mathrm{b}}$ Brian F. Buxton, FRCS, FRACS, ${ }^{\mathrm{b}}$ Andrew G. Stewart, BA, ${ }^{\mathrm{c}}$ and \\ David L. Hare, PhD, FRACP
}

\begin{abstract}
Objective: The radial artery (RA) has gained popularity as a conduit for coronary artery bypass surgery despite a paucity of patient-centered analysis of long-term quality of life after its removal. We sought to characterize forearm function and symptoms after RA harvest and compare these with those associated with saphenous vein (SV) removal.
\end{abstract}

\begin{abstract}
Methods: A total of 408 patients from an RA trial completed a questionnaire up to 14 years after primary coronary artery bypass surgery. The survey included 7 statements concerning hand and forearm symptoms or limitations in daily life and 4 questions on concerns associated with arm or leg scars. A total of 230 patients had received an RA graft (RA group). Responses were graded in order of severity from 0 to 7 , with greater than 3 (mild concern) being regarded as a significant symptom. Mean response to each question and total scores were compared with the nonRA harvest group. Comparisons were also made with responses to the same questionnaire completed preoperatively and 3 months postoperatively. In patients who had both RA and SV removal, we compared the impact of a forearm scar on quality of life with that of a leg scar.
\end{abstract}

Results: The mean duration of follow-up was 9.3 years (range, $4-14$ years), and the response rate was $83 \%$. In the RA group, $92 \%$ to $99 \%$ reported no significant symptoms, with the most frequent concerns relating to pain and numbness ( $8 \%$ each), but this was not significantly higher than in those who had not had an RA harvested. In the RA group, the mean scores for scar appearance and discomfort were 0.95 and 0.93 , respectively (where $1=$ no concern), suggesting satisfactory cosmesis and no impact on function. Symptom severity was significantly worse in 6 of 7 questions when compared with preoperative responses and in 4 of 7 items compared with 3-month follow-up, indicating a general deterioration in function over long-term follow-up. In those who had both the RA and SV harvested, patients reported more scar discomfort associated with SV harvest at 3 months $(1.69$ vs $1.34, P<.001)$ and in the present questionnaire $(1.21$ vs $0.97, P=.002)$. Concerns with scar appearance were no different between the arm and leg.

Conclusions: RA harvesting is associated with high patient satisfaction and less scar discomfort than SV removal. Overall, functionality declines with time, and a small proportion of patients seem to experience forearm pain and numbness. However, this is not different than in those without artery removal and may therefore be unrelated to the effects of surgery. (J Thorac Cardiovasc Surg 2013;145:412-9)

First introduced in the early $1970 \mathrm{~s}^{1}$ during coronary artery bypass grafting, the radial artery (RA) has gained increasing popularity as a conduit used alternatively or in addition to the saphenous vein (SV). Encouraging angiographic outcomes have been described, ${ }^{2-5}$ and its merit over the $\mathrm{SV}$ is currently being investigated as part of randomized controlled trials. ${ }^{6,7}$ However, there is a relative paucity of

\footnotetext{
From The University of Melbourne, ${ }^{\text {a }}$ Melbourne Medical School, Melbourne, Victoria, and Departments of Cardiac Surgery ${ }^{\mathrm{b}}$ and Cardiology, ${ }^{\mathrm{c}}$ Austin Health, Melbourne, Victoria, Australia.

Disclosures: Authors have nothing to disclose with regard to commercial support. Received for publication Aug 16, 2011; revisions received Dec 20, 2011; accepted for publication Jan 4, 2012; available ahead of print Feb 24, 2012.

Address for reprints: Ying Yan Zhu, BMedSc, Cardiac Surgery, Level 5 HSB, Austin Health, 145 Studley Road Heidelberg, Melbourne, Victoria, Australia (E-mail: yingyan.zhu@gmail.com).

0022-5223/\$36.00

Copyright (C) 2013 by The American Association for Thoracic Surgery doi:10.1016/j.jtcvs.2012.01.052
}

data on long-term hand and forearm function after RA harvest, particularly in relation to its impact on quality of life, which might deter some surgeons from using this conduit. Previous studies have investigated the effect of RA removal in the immediate postoperative period, with reports of minor complications, including pain, numbness, and wound infection. ${ }^{8,9}$ Midterm outcomes up to 2 years postoperatively have suggested continuing concerns of neurologic complication. ${ }^{10-12}$ We aimed to characterize long-term hand and forearm function up to 14 years after RA removal and to compare this with symptoms reported after SV removal in the same cohort of patients.

\section{MATERIALS AND METHODS Patients}

Patients in this study were previously enrolled in the Radial Artery Patency and Clinical Outcomes Trial (RAPCO). ${ }^{7}$ The primary aim of RAPCO was to investigate the long-term patency and clinical outcomes of the RA 


\author{
Abbreviations and Acronyms \\ $\mathrm{RA} \quad=$ radial artery \\ RAPCO $=$ Radial Artery Patency and Clinical \\ Outcomes Trial \\ $\mathrm{SV} \quad=$ saphenous vein
}

compared with the right internal thoracic artery or SV when grafted to the second non-left anterior descending target. The study population comprises 2 groups: Group 1 included patients aged less than 70 years who were randomized $1: 1$ to receive an RA or right internal thoracic artery, and group 2 included patients aged 70 years or more who were randomized 1:1 to an RA or SV. Any subsequent grafts normally used the SV. Patients receive annual clinical review by a cardiac surgeon and cardiologist combined with telephone follow-up by an experienced clinical trials nurse for a minimum of 10 years, during which they undergo a predetermined protocol of angiograms.

\section{Harvesting Technique}

All conduits were harvested with scissors and hemoclips using a notouch technique and meticulous dissection. The arm incision extends approximately from $2 \mathrm{~cm}$ below the level of the elbow to $2 \mathrm{~cm}$ above the wrist, in the line of the RA. SVs were removed through an incision along the medial aspect of the calf extending to $2 \mathrm{~cm}$ above the medial malleolus. Because procedures were performed between 1997 and 2004, endoscopic techniques were not used.

\section{Quality of Life Data}

A secondary aim of RAPCO was to assess any differences in quality of life associated with use of the different conduits. As such, all participants in RAPCO were asked to complete a questionnaire (Figure 1) before surgery and at 3,6, and 12 months postoperatively. The results of the 3- and 12month data have been published ${ }^{13,14}$ but do not necessarily reflect mature healing or longer-term impacts.

This questionnaire was designed by the trial investigators at the commencement of the study in conjunction with researchers experienced in quality of life assessment tools and includes a mixture of well-validated health surveys (Short Form-8, Mobility-Cardiovascular Limitations and Symptoms Profile, and Cardiac Depression Scale) and a novel hand function assessment containing questions specifically targeted at elucidating hand and forearm symptoms. Internal validation was performed on the previously published data. The same survey was reused in this study to allow direct comparisons with the earlier data.

All surviving patients under trial surveillance were asked to complete the questionnaire to evaluate hand and forearm function and its effects on quality of life in the long-term. If there was no reply after a period of 2 weeks, the questionnaire was mailed again and supplemented by a verbal request by telephone. We attempted to complete any missing data on the returned forms by further telephone contact with the patient. The survey contained 7 questions regarding forearm function and symptoms, 2 questions on scar appearance and discomfort in the arm, and 2 questions on scar appearance and discomfort in the leg. Responses were graded in order of severity from 0 to 7 , with 3 being a mild symptom or concern and any score greater than 3 regarded as clinically significant. The total score was calculated from the sum of responses from questions 2 to 7 (question 1 was excluded because its response was non-numeric). Total scores were divided into 3 categories for multivariate analysis: category A (where individual scores for questions 2 to 7 were 1 ; score $=6$ ) indicates no symptoms at all, category B (where at least 1 question scored greater than 1 but none was greater than 3 , the threshold for clinical significance; $7 \leq$ score $\leq 18$ ) indicates the presence of symptoms that are not clinically significant, and category $\mathrm{C}$ (at least 1 question scored higher than 3 ; score $>18$ ) indicates clinically significant symptoms. Patients who had not had an RA removed were requested to respond to the same questions based on the function of their nondominant hand.

The average scores and proportion of patients within the RA group who experienced significant symptoms in the present questionnaire were evaluated against those who had no arm incisions (non-RA group). Comparisons were also made with preoperative and 3-month postoperative data to assess changes in quality of life and hand function over time. Patient characteristics such as age, sex, and number of grafts were used in a logistic regression model to determine which of these, if any, were predictors of poorer longterm forearm function reflected in higher total scores.

To characterize any differences in quality of life after RA removal versus that of SV harvest, patients were analyzed via 2 methods. First, in patients who had received both RA and SV grafts irrespective of randomization, we evaluated forearm scar concerns against leg scar problems at 3 months postoperatively and in the present questionnaire after long-term follow-up. Second, in the original RAPCO protocol, patients in group 2 were randomized to the RA or SV, and we compared forearm or leg scar concerns in these groups whose incisions were dictated by randomization, recognizing that this may influence patients' perspective of these.

\section{Statistical Methods}

All analyses were performed using SPSS statistical software (SPSS Inc 2010, PASW Statistics 18; IBM Corp, Somers, NY). Comparisons between RA and non-RA groups were conducted using unpaired $t$ tests. For comparisons with preoperative data and 3-month data and for determination of scar concerns, paired $t$ tests were used. We used multinomial logistic regression to assess multivariate predictors of poorer total score outcomes.

\section{RESULTS}

\section{Study Population}

There were 619 patients originally enrolled in RAPCO. Of these, 491 were alive at the time of our study after an average follow-up of 9.3 years (range, $4-14$ years). A total of 408 patients completed our questionnaire, giving an overall response rate of $83 \%$. Among pooled respondents, 231 patients received an RA by randomization and 177 had no forearm incision (randomized to right internal thoracic artery or SV depending on whether in group 1 or 2). A total of 168 patients had received both RA and SV grafts.

A separate analysis was made of group 2, wherein incisions were mandated by randomization rather than by the need for supplementary nonrandomized grafts: In group 2, 125 patients returned the questionnaire, of whom 69 had received an RA (group $2 \mathrm{RA}$ ) and 56 had not (group $2 \mathrm{SV}$ ).

There were no significant differences in baseline demographics between the RA and non-RA groups and between the group $2 \mathrm{RA}$ and group $2 \mathrm{SV}$ respondents (Table 1). Among respondents in group 2, the average number of grafts in group $2 \mathrm{SV}$ was slightly higher (3.30 vs $3.04, P=.054$ ), although this apparent difference in respondents does not occur in the full randomized cohorts under long-term follow-up.

\section{Effect of Radial Artery Removal on Long-Term Quality of Life}

Responses from the RA group (Table 2) show average scores ranging from 0.9 to 1.6 , with $90 \%$ of respondents answering positively to a question regarding general 


\section{Hand Function Questionnaire}

Instructions: This questionnaire consists of a number of statements about the sensation and use of your non-dominant arm and hand. If you are right handed, it refers to your left arm and vice versa. If you have had the radial artery removed, it applies to this arm and hand. These questions relate to how your hand feels now.

\section{Right now, my hand and arm appear to be fine?}

$$
\bigcirc_{1} \text { Yes } \quad \bigcirc_{2} \text { No }
$$

\section{I feel pain in my arm or hand}

\begin{tabular}{l|l}
1 & no pain at all \\
\hline 2 & trivial \\
3 & mild \\
4 & moderate \\
5 & quite severe \\
6 & severe \\
7 & severe, unbearable pain
\end{tabular}

\section{I feel numbness in my arm or hand}

\begin{tabular}{l|l}
1 & no numbness at all \\
2 & trivial \\
3 & mild \\
4 & moderate \\
5 & quite severe \\
6 & severe \\
7 & severe, unbearable numbness
\end{tabular}

\section{My arm or hand is swollen}

\begin{tabular}{l|l}
1 & no swelling at all \\
2 & trivial \\
3 & mild \\
4 & moderate \\
\hline 5 & quite severe \\
6 & severe \\
7 & severe, unbearable swelling
\end{tabular}

\section{I have limited use of my hand}

\begin{tabular}{l|l}
1 & no limitations at all \\
2 & trivial \\
3 & mild \\
4 & moderate \\
5 & quite severe \\
6 & severe \\
\hline 7 & extremely limited use \\
\hline
\end{tabular}

\section{I am concerned about the appearance of my arm scar}

\begin{tabular}{l|l}
0 & no scar at all \\
1 & no concern \\
2 & trivial concern \\
3 & mild \\
4 & moderate \\
5 & quite concerned \\
6 & very concerned \\
7 & extremely concerned
\end{tabular}

\section{My arm has a scar that causes discomfort}

\begin{tabular}{l|l}
0 & no scar at all \\
1 & no discomfort \\
2 & trivial discomfort \\
3 & mild \\
4 & moderate \\
5 & quite uncomfortable \\
6 & very uncomfortable \\
7 & extremely uncomfortable
\end{tabular}

FIGURE 1. Hand function questionnaire. 


\section{I have difficulties with daily tasks because of the use of my hand and arm}

\begin{tabular}{l|l}
1 & no difficulties at all \\
2 & trivial difficulties \\
3 & mild \\
4 & moderate \\
5 & quite marked \\
6 & very marked \\
7 & extremely marked
\end{tabular}

Comments:

\section{Overall, my life is affected by the problems} with my hand or arm

\begin{tabular}{l|l}
1 & no worse at all \\
\hline 2 & trivial life disruptions \\
\hline 3 & mild \\
\hline 4 & moderate \\
\hline 5 & quite marked \\
6 & marked \\
7 & life radically worse \\
\hline
\end{tabular}

Comments:

FIGURE 1. (Continued)

functionality and $96 \%$ of patients scoring a total of 18 or less, the threshold for clinically significant symptoms. The most frequent concerns were those relating to arm pain and numbness, with $8.4 \%$ and $8.3 \%$ experiencing significant symptoms, respectively. However, average scores, total scores, and the prevalence of significant symptoms were not different between the RA and non-RA groups in any of the questions.

Scar appearance and discomfort in the arm scored averages of 0.95 and 0.93 , respectively (where $1=$ no concern/ discomfort), suggesting satisfactory cosmesis and wound healing. Of the patient characteristics analyzed, only diabetes (Table 3) was significantly associated with worse long-term outcomes. Diabetic status was predictive of the presence of any symptoms (category B) and significant symptoms (category C).
10. I have had coronary surgery using my leg vein and I am concerned about the appearance of the leg scar

0 no scar at al

1 no concern

2 trivial concern

3 mild

4 moderate

5 quite concerned

6 very concerned

7 extremely concerned

Comments:

\section{My leg has a scar that causes discomfort}

0 no scar at all

1 no discomfort

2 trivial discomfort

3 mild

4 moderate

5 quite uncomfortable

6 very uncomfortable

7 extremely uncomfortable

Comments:

Trends Over Time: Preoperative, 3-Month, and Long-Term Data

Of the 408 patients who returned the present questionnaire, 280 and 295 had available preoperative and 3-month data, respectively (Table 4). Overall, symptom severity for the forearm was significantly higher in 6 of 7 questions compared with preoperative responses (Table 2), indicating general deterioration in function (or perception of function) over long-term follow-up, irrespective of conduit harvesting. The only concern that did not worsen was arm swelling. Likewise, overall responses were significantly higher in 4 of the 7 items compared with 3-month follow-up, confirming this pattern of deterioration with increasing age. In the RA group, numbness was worst at 3 months, with improvement seen after long-term follow-up. When combined with 
TABLE 1. Baseline demographics

\begin{tabular}{|c|c|c|c|c|c|c|}
\hline & \multicolumn{3}{|c|}{ RA vs non-RA group } & \multicolumn{3}{|c|}{ Randomized groups: Group 2 RA vs group 2 SV } \\
\hline & $\mathbf{R A} \mathbf{n}=\mathbf{2 3 1}(\%)$ & Non-RA n $=177(\%)$ & $P$ value & $\mathbf{R A} \mathbf{n}=\mathbf{6 9}(\%)$ & $\mathbf{S V} \mathbf{n}=\mathbf{5 6}(\%)$ & $P$ value \\
\hline Age, y & 62.9 & 63.4 & .633 & 72.4 & 72.1 & .765 \\
\hline Sex (male) & $197(85)$ & $155(88)$ & .582 & $55(78)$ & $46(81)$ & .655 \\
\hline Smoking (never) & $73(32)$ & $51(29)$ & .745 & $27(38)$ & $20(35)$ & .928 \\
\hline Smoking (previous) & $142(62)$ & $112(63)$ & .745 & $42(59)$ & $35(61)$ & .928 \\
\hline Smoking (current) & $15(6.5)$ & $14(7.9)$ & .745 & $2(2.8)$ & $2(3.5)$ & .928 \\
\hline Diabetes & $43(19)$ & $38(22)$ & .501 & $29(41)$ & $25(44)$ & .783 \\
\hline Preoperative hypertension & $129(56)$ & $96(54)$ & .710 & $41(58)$ & $37(65)$ & .409 \\
\hline Surgery status (no. urgent) & $34(15)$ & $29(17)$ & .605 & $12(18)$ & $7(13)$ & .408 \\
\hline Mean no. of grafts & 3.15 & 3.15 & .997 & 3.04 & 3.30 & .054 \\
\hline
\end{tabular}

$R A$, Radial artery; $S V$, saphenous vein.

a small, nonsignificant increase in reported numbness in the non-RA group, there was a small decline in numbness on average in the pooled data. This was the only symptom that improved over time. The decline in function as assessed by total score was therefore significant only for the non-RA group. This was less marked and nonsignificant in the RA group because it was offset by the improvement (reduction in score) in numbness.

\section{Scar Concerns of Radial Artery Versus Saphenous Harvest}

In those who sustained both arm and leg scars (Table 5), at 3 months after surgery patients reported significantly greater discomfort associated with the leg scar $(P<.001)$ than with the arm scar but no difference in concerns regarding scar appearance. Analysis of data from the long-term follow-up questionnaire revealed a similar pattern of responses, with greater concern for leg discomfort $(P=.002)$ compared with forearm discomfort, but again, no differences in terms of appearance. These results indicate greater satisfaction with RA removal that is sustained in the long-term. The percentage of improvement in scar discomfort over time is equal in both the arm and the leg at $28 \%$.

In the randomized comparison from group 2 (Table 6), scar discomfort in the leg trended toward being greater in patients with $\mathrm{SV}(P=.066)$, with no differences in concern with appearance.

\section{DISCUSSION}

Arterial conduits, including the RA, are increasingly preferred in some centers performing coronary revascularization. Studies of postoperative donor site complications after RA harvest have largely been reassuring, with low rates of complications such as motor dysfunction, ischemia, and infection. ${ }^{15-17}$ Despite this, paresthesia of the hand can be problematic, with reported rates of approximately $11 \%{ }^{16}$ and $19 \% .{ }^{14}$ Whether these concerns improve over time is unclear. We sought to characterize this further.

Approximately 10 years after coronary surgery, all questions in our survey had a mean score less than 2 ( 2 being trivial concerns or difficulties), indicating that, on the whole, RA removal is associated with high long-term patient satisfaction. The total score (the sum of responses to

TABLE 2. Forearm function and symptoms: Comparison of radial artery group versus non-radial artery group after long-term follow-up (current questionnaire)

\begin{tabular}{|c|c|c|c|c|c|c|c|c|}
\hline Question & & & $\begin{array}{r}\text { RA group } \\
(\mathbf{n}=\mathbf{2 3 1})\end{array}$ & & $\begin{array}{l}\text { Non-RA group } \\
\quad(n=177) \\
\end{array}$ & & $\begin{array}{c}\text { Comparison of } \\
\text { proportion with } \\
\text { score } \leq 3 \\
\end{array}$ & $\begin{array}{c}\text { Comparison } \\
\text { of mean } \\
\text { scores } \\
\end{array}$ \\
\hline no. & Symptom & Range & Score $\leq \mathbf{3}^{*}(\%)$ & Mean score & Score $\leq \mathbf{3}^{*}(\%)$ & Mean score & $P$ value & $P$ value \\
\hline 1 & Satisfaction with overall functionality & $\mathrm{Y}, \mathrm{N}$ & N/A & $90 \%$ for $\mathrm{Y}$ & N/A & $91 \%$ for $\mathrm{Y}$ & N/A & .41 \\
\hline 2 & Pain & $1-7$ & 91.6 & 1.57 & 90.1 & 1.69 & .61 & .30 \\
\hline 3 & Numbness & $1-7$ & 91.7 & 1.61 & 93.0 & 1.60 & .63 & .90 \\
\hline 4 & Swelling & $1-7$ & 98.7 & 1.15 & 96.5 & 1.23 & .15 & .24 \\
\hline 5 & Limitation on use & $1-7$ & 94.8 & 1.35 & 93.1 & 1.43 & .47 & .43 \\
\hline 6 & Difficulties with daily tasks & $1-7$ & 94.3 & 1.41 & 90.6 & 1.49 & .16 & .48 \\
\hline 7 & Overall effect on life & $1-7$ & 96.0 & 1.36 & 92.9 & 1.45 & .17 & .39 \\
\hline 8 & Total score (questions 2-7) & $6-42$ & $95.6 \dagger$ & 8.47 & $95.2 \dagger$ & 8.76 & .859 & .73 \\
\hline 9 & Arm scar appearance & $0-7$ & 98.7 & 0.95 & - & - & - & - \\
\hline 10 & Arm scar discomfort & $0-7$ & 98.7 & 0.93 & - & - & - & - \\
\hline
\end{tabular}

$R A$, Radial artery. *Score $\leq 3$ indicates no clinically significant symptoms. $\dagger$ Total score $\leq 18$ indicates no clinically significant symptoms. 
TABLE 3. Logistic regression of factors affecting quality of life

\begin{tabular}{|c|c|c|c|c|c|c|}
\hline & \multicolumn{3}{|c|}{ Total score: category $\mathbf{B}^{*}$} & \multicolumn{3}{|c|}{ Total score: category $\mathbf{C}^{*}$} \\
\hline & OR & CI & $P$ value & OR & CI & $P$ value \\
\hline Age & 1.01 & $(0.99-1.03)$ & .487 & 1.05 & $(0.99-1.11)$ & .146 \\
\hline No grafts & 0.92 & $(0.69-1.21)$ & .544 & 1.49 & $(0.78-2.89)$ & .230 \\
\hline Smoking (never) $\dagger$ & 1.11 & $(0.70-1.78)$ & .659 & 0.56 & $(0.16-1.95)$ & .364 \\
\hline Sex (female) & 0.57 & $(0.57-2.09)$ & .787 & 1.36 & $(0.37-5.07)$ & .644 \\
\hline No diabetes & 0.56 & $(0.33-0.96)$ & .036 & 0.18 & $(0.06-0.50)$ & .001 \\
\hline No hypertension & 0.98 & $(0.63-1.50)$ & .909 & 0.83 & $(0.29-2.40)$ & .729 \\
\hline Elective surgical status & 0.83 & $(0.455-1.51)$ & .541 & 0.36 & $(1.08-1.21)$ & .098 \\
\hline
\end{tabular}

$O R$, Odds ratio; $C I$, confidence interval. *Category A: total score $=6$; Category B: $7 \leq$ total score $\leq 18$; Category C: total score $>18$. ORs are calculated using category A as reference. $\dagger$ Smoking (never) is compared with smoking (previous or current).

questions 2-7) reflects this, with more than $95 \%$ of respondents reporting no symptoms or minor symptoms that are not clinically significant. However, there were still some patients who experienced significant problems, with approximately $8 \%$ reporting pain or numbness. In another reported series of 211 patients interviewed for neurologic symptoms of the hand after a mean follow-up of 26 months, $10 \%$ to $15 \%$ experienced minor neurologic complications such as numbness or hyposensitivity. ${ }^{11}$ Our satisfaction rates are at least comparable to this, despite the significantly longer follow-up time. The prevalence of numbness after RA harvest was highest at 3 months after surgery (Table 4), but this

TABLE 4. Trends over time for all patients: Preoperative, 3-month, and long-term data (current questionnaire)

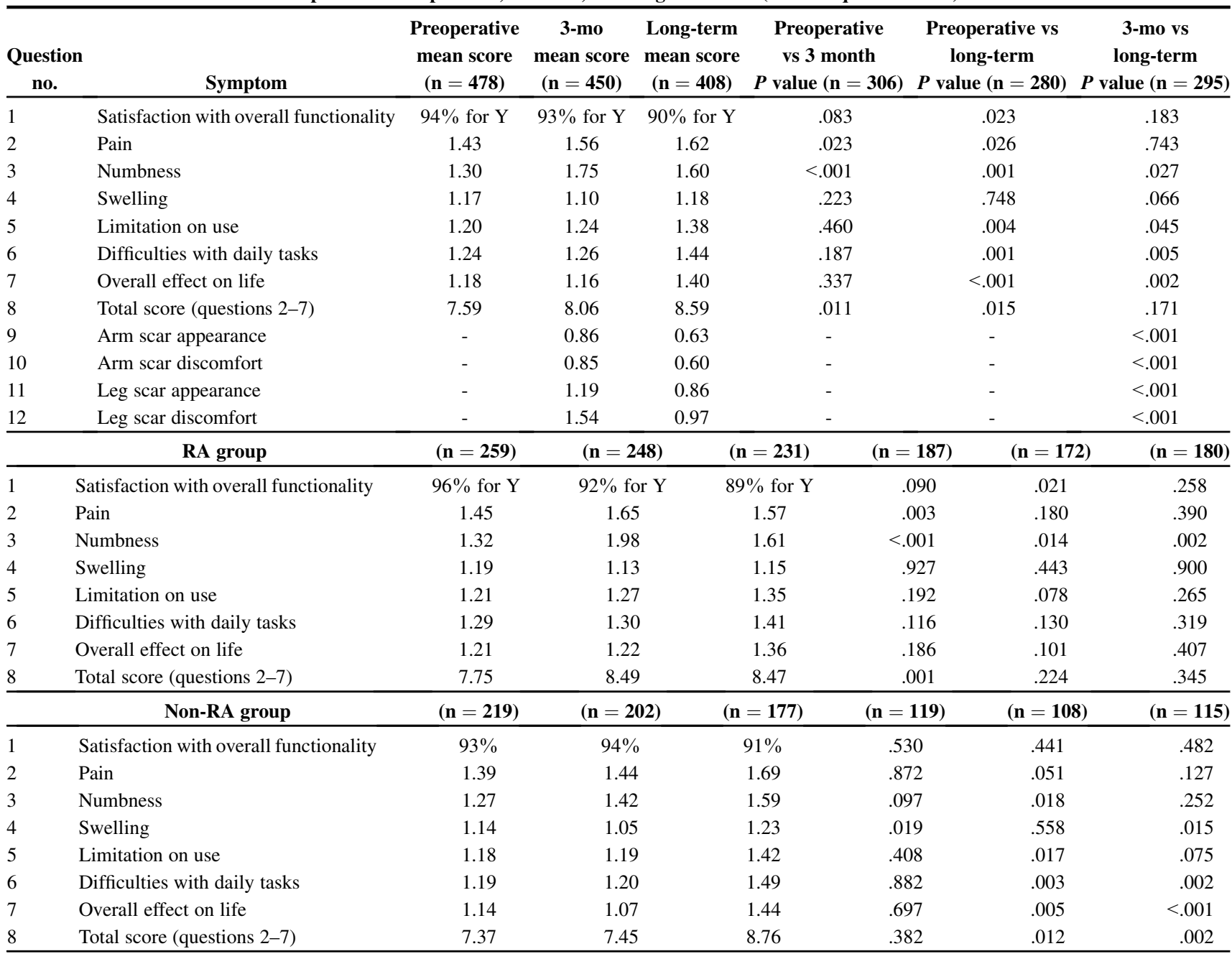


TABLE 5. Comparison of arm and leg scars in patients with both radial artery and saphenous vein removal: Scar appearance and discomfort

\begin{tabular}{|c|c|c|c|c|}
\hline & $\begin{array}{c}3 \text { mo } \\
\text { postoperatively } \\
(\mathbf{n}=166) \\
\end{array}$ & $\begin{array}{l}\text { Long-term } \\
\text { follow-up } \\
(n=168) \\
\end{array}$ & $\begin{array}{c}\text { Change } \\
\text { in mean } \\
\text { score }(\%) \\
\end{array}$ & $P$ value \\
\hline \multicolumn{5}{|c|}{ Scar discomfort } \\
\hline Leg & 1.69 & 1.21 & -28 & $<.001$ \\
\hline Arm & 1.34 & 0.97 & -28 & $<.001$ \\
\hline \multicolumn{5}{|c|}{ Comparison of arm vs leg } \\
\hline$P$ value & $<.001$ & .002 & & \\
\hline \multicolumn{5}{|c|}{ Scar appearance } \\
\hline Leg & 1.30 & 1.01 & -22 & $<.001$ \\
\hline Arm & 1.37 & 0.93 & -32 & $<.001$ \\
\hline \multicolumn{5}{|c|}{ Comparison of arm vs leg } \\
\hline$P$ value & .32 & .18 & & \\
\hline
\end{tabular}

Values shown represent mean scores.

declined during long-term follow-up. Two other studies evaluating midterm outcomes at 15 and 16 months reported higher complication rates of motor and sensory abnormalities in $30 \%$ and $34 \%$ of patients, respectively. ${ }^{10,12}$ It is possible that the more favorable results in our study and that of Knobloch and colleagues ${ }^{11}$ may be attributed to the longer lengths of follow-up, allowing more time for functional recovery of the hand. Experience levels of surgeons harvesting RAs in our series also may have been higher, with the potential for less tissue dissection or nerve injury.

When the long-term follow-up questionnaire scores are compared with those obtained preoperatively, mean responses show increased concern for hand and forearm symptoms in 6 of 7 questions after follow-up, indicating a general decline in function during a 10 -year period. Comparisons with the 3-month data support this observation, where responses to 4 of the 7 questions scored higher in the present questionnaire than at 3 months (Table 4). This is consistent with a pattern of deterioration that occurs gradually over 10 years. Neither the average scores nor the incidence of significant symptoms differed between the RA and non-RA groups (Table 2) for any of the questions after long-term follow-up, again suggesting that the observed deterioration from preoperative levels may be an aging phenomenon unrelated to the effects of conduit harvesting.

It is notable that scar appearance is rarely of major concern to patients, regardless of whether in the arm or leg, with low mean scores for both in the pooled data (0.93 vs $1.01, P=.18$, Table 5) and when determined by randomization in group 2 ( 0.84 vs $0.96, P=.27$, Table 6 ).

RA use offers an advantage over that of the SV in terms of discomfort, and this is true at 3 months postoperatively and continues to be so more than a decade later when all patients are analyzed (discomfort score 0.97 vs $1.21, P=.002$, Table 5). The randomized comparisons in group 2
TABLE 6. Randomized group 2 comparison of radial artery and saphenous vein: Scar appearance and discomfort

\begin{tabular}{lccc}
\hline & $\begin{array}{c}\text { Group 2 RA } \\
(\mathbf{n}=\mathbf{6 9})\end{array}$ & $\begin{array}{c}\text { Group 2 SV } \\
(\mathbf{n}=\mathbf{5 6})\end{array}$ & $\begin{array}{c}\boldsymbol{P} \\
\text { value }\end{array}$ \\
\hline Arm/leg scar discomfort & 0.88 & 1.14 & .066 \\
Arm/leg scar appearance & 0.84 & 0.96 & .268 \\
\hline$R A$, Radial artery; $S V$ saphenous vein. Values shown represent mean scores.
\end{tabular}

$R A$, Radial artery; $S V$, saphenous vein. Values shown represent mean scores.

(Table 6) support these results, with a strong trend that favors the forearm but fails to reach statistical significance, most likely because of the smaller number of patients in this cohort. The mean number of grafts was higher in respondents in group 2 who were randomized to receive the $\mathrm{SV}(P=.054$, Table 1$)$. Although the reasons for this are unclear, because this does not reflect the full group 2 cohort, it is possible that patients who received more grafts had longer leg incisions. However, the difference in means is only 0.26 grafts per patient, or 1 graft per 4 patients, which does not seem enough to account for the differences noted in scar discomfort.

A recent study by Hill and colleagues ${ }^{18}$ examined patient satisfaction with arm and leg scars via a questionnaire 6 weeks after coronary surgery. This study reported that patients who had been given a choice in conduit site selection responded with more favorable scar ratings. We assessed scar perceptions in patients randomized to SV (in group 2) and in patients who had received vein grafts as a nonrandomized accessory conduit to determine whether preoperative knowledge of scar site affected patient perception. There were no differences in ratings of scar appearance and discomfort at 3 months and after long-term follow-up.

\section{Study Limitations}

Despite our efforts to contact all nonresponders by telephone, a higher number of questionnaire responses were obtained from patients who received an RA than from those who had not (231 vs 177 overall and in the randomized groups, 69 vs 56). The cause of this is unclear, but may reflect an inherent bias toward cooperation with such substudies among patients who receive a particular treatment arm, particularly one included in the trial name.

There has been recent interest in the outcomes of minimally invasive techniques for conduit harvesting. Our study cannot address this because all conduits in this series were removed via conventional open methods, because endoscopic techniques were not widely used at the time most of these procedures were performed. Furthermore, any differences in the surgery itself may have affected graft patency (the primary outcome measure of RAPCO). As such, no direct comparisons can be made in this regard.

Reports in the literature seem to favor the use of endoscopic radial harvesting over that of conventional techniques in terms of donor site complications. Bleiziffer and 
colleagues ${ }^{19}$ and Medalion and colleagues ${ }^{20}$ report superior overall outcomes with endoscopic radial removal approximately 1 year after surgery, despite the higher rates of neurologic complications of the arm in the endoscopic group of Bleiziffer and colleagues. However, the same can be said of endoscopic vein harvest. Kiaii and colleagues ${ }^{21}$ reported significantly reduced postoperative leg wound complications associated with minimally invasive techniques. Therefore, it may still hold that RAs are better than veins when both are harvested endoscopically. Whether the endoscopic vein is better than the open RA remains to be clarified. There have been some concerns regarding graft performance after endoscopic methods, and any measures and comparisons of quality of life must account for this potential trade-off in patency.

\section{CONCLUSIONS}

RA harvest is associated with minor residual concerns in a small proportion of patients after long-term follow-up but is largely favorably perceived by patients. Hand and forearm function deteriorate over time, but this occurs irrespective of conduit harvesting from that limb and more likely reflects an aging-related phenomena. RA harvesting seem to cause less scar discomfort than SV removal, both in the short and long term. This supports the widespread use of the RA in coronary surgery if angiographic and clinical outcomes are equivalent or superior to those of the SV.

\section{References}

1. Carpentier A, Guermonprez J, Deloche A, Frechette C, DuBost C. The aorta-tocoronary radial artery bypass graft. A technique avoiding pathological changes in grafts. Ann Thorac Surg. 1973;16:111-21.

2. Acar C, Ramsheyi A, Pagny J, Jebara V, Barrier P, Fabiani J-N, et al. The radial artery for coronary artery bypass grafting: clinical and angiographic results at five years. Cardiovasc Surg. 1998;116:981-9.

3. Iaco A, Teodori G, Di Giammarco G, Di Mauro M, Storto L, Mazzei V, et al. Radial artery for myocardial revascularization: long-term clinical and angiographic results. Ann Thorac Surg. 2001;72:464-8.

4. Possati G, Gaudino M, Prati F, Alessandrini F, Trani C, Glieca F, et al. Long-term results of the radial artery used for myocardial revascularization. Circulation. 2003;108:1350-4
5. Tatoulis J, Royse AG, Buxton BF, Fuller JA, Skillington PD, Goldblatt JC, et al. The radial artery in coronary surgery: a 5-year experience-clinical and angiographic results. Ann Thorac Surg. 2002;73:143-7.

6. Fremes SE. Multicenter Radial Artery Patency Study (RAPS): study design. Control Clin Trials. 2000;21:397-413.

7. Buxton BF, Raman JS, Ruengsakulrach P, Gordon I, Rosalion A, Bellomo R, et al. Radial artery patency and clinical outcomes: five-year interim results of a randomized trial. J Thorac Cardiovasc Surg. 2003;125:1363-70.

8. Hata M, Shiono M, Sezai A, Iida M, Saitoh A, Hattori T, et al. Comparative study of harvest-site complications following coronary artery bypass grafting between the radial artery and the saphenous vein in identical patients. Surg Today. 2005; 35:711-3.

9. Chong WCF, Ong PJL, Hayward CS, Collins P, Moat NE. Effects of radial artery harvesting on forearm function and blood flow. Ann Thorac Surg. 2003;75:1171-4

10. Siminelakis S, Karfis E, Anagnostopoulos C, Toumpoulis I, Katsaraki A Drossos G. Harvesting radial artery and neurologic complications. J Card Surg. 2004;19:505-10.

11. Knobloch K, Lichtenberg A, Tomaszek S, Hagl C, Khaladj N, Klima U, et al. Long-term physical activity and neurologic function after harvesting of the radial artery as T-graft or free graft in coronary revascularization. Ann Thorac Surg. 2005;80:918.

12. Denton TA, Trento L, Cohen M, Kass RM, Blanche C, Raissi S, et al. Radial artery harvesting for coronary bypass operations: neurologic complications and their potential mechanisms. J Thorac Cardiovasc Surg. 2001;121:951-6.

13. Hata M, Raman J, Seevanayagam S, Hare D, Buxton BF. Post radial artery harvest hand perception: postoperative 12-month follow-up results. Circ J. 2002;66: 916.

14. Hata M, Raman J, Matalanis G, Rosalion A, Storer M, Hare D, et al. Post harvest wound infection and patient's perception: comparative study between radial artery and saphenous vein harvest sites. Ann Thorac Cardiovasc Surg. 2002;8: 97-101.

15. Ikizler M, Ozkan S, Dernek S, Ozdemir C, Erdinc OO, Sevin B, et al. Does radia artery harvesting for coronary revascularization cause neurological injury in the forearm and hand? Eur J Cardiothorac Surg. 2005;28:420-4.

16. Greene MA, Malias MA. Arm complications after radial artery procurement for coronary bypass operation. Ann Thorac Surg. 2001;72:126-8.

17. Budillon AM, Nicolini F, Agostinelli A, Beghi C, Pavesi G, Fragnito C, et al. Complications after radial artery harvesting for coronary artery bypass grafting: our experience. Surgery. 2003;133:283-7.

18. Hill C, Shepherd J, Birdi I. Satisfaction with conduit harvest site scars in coronary bypass surgery. Ann R Coll Surg Engl. 2011;93:297-300.

19. Bleiziffer S, Hettich I, Eisenhauer B, Ruzicka D, Voss B, Bauernschmitt R, et al. Neurologic sequelae of the donor arm after endoscopic versus conventional radial artery harvesting. J Thorac Cardiovasc Surg. 2008;136:681-7.

20. Medalion B, Fuks A, Sharoni E, Stamler A, Snir E, Vidne B, et al. Limb performance and patient satisfaction after radial artery harvesting: endoscopic versus open techniques. Surg Endosc. 2008;22:2638-42.

21. Kiaii B, Moon B, Massel D, Langlois Y, Austin T, Willoughby A, et al. A prospective randomized trial of endoscopic versus conventional harvesting of the saphenous vein in coronary artery bypass surgery. J Thorac Cardiovasc Surg. 2002; 123:204-12. 